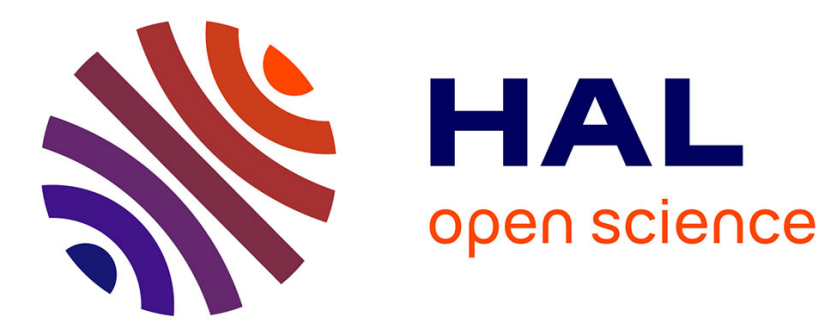

\title{
Enantioselective Ir-Catalyzed Bidirectional Reductive Coupling
}

\author{
Adrien Quintard, Jean Rodriguez
}

\section{To cite this version:}

Adrien Quintard, Jean Rodriguez. Enantioselective Ir-Catalyzed Bidirectional Reductive Coupling.

Organic Letters, 2019, 21 (2), pp.453-456. 10.1021/acs.orglett.8b03669 . hal-01987319

\section{HAL Id: hal-01987319 \\ https://hal.science/hal-01987319}

Submitted on 21 Jan 2019

HAL is a multi-disciplinary open access archive for the deposit and dissemination of scientific research documents, whether they are published or not. The documents may come from teaching and research institutions in France or abroad, or from public or private research centers.
L'archive ouverte pluridisciplinaire HAL, est destinée au dépôt et à la diffusion de documents scientifiques de niveau recherche, publiés ou non, émanant des établissements d'enseignement et de recherche français ou étrangers, des laboratoires publics ou privés. 


\title{
Enantioselective Ir-Catalyzed Bidirectional Reductive Coupling
}

\author{
Adrien Quintard*๑ and Jean Rodriguez \\ Aix Marseille Univ, CNRS, Centrale Marseille, iSm2, Marseille 13397, France
}

ABSTRACT: In the presence of a chiral iridium complex, commercially available 3-chloro-2-chloromethyl-1-propene (1) was selectively activated for various reductive couplings. Depending on the reaction conditions it allows a selective mono- or bidirectional condensation with one or two external aldehydes with excellent enantiocontrol (>90\% ee). This approach occurring simply under mild conditions and avoiding premetalated reagents constructs rapidly chiral homoallylic alcohols, key precursors of important molecular fragments such as furans, pyrans, ketodiols, or 1,3,5-polyols.

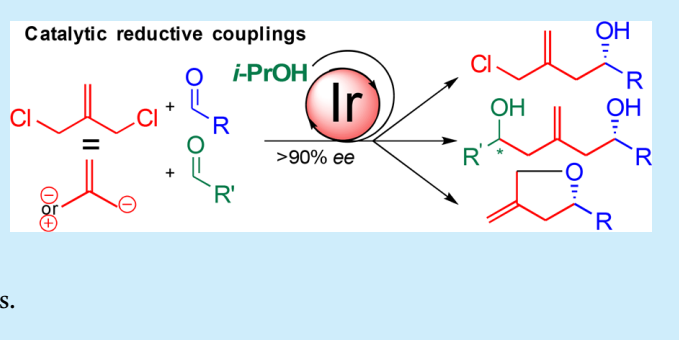

A ssembling simple building blocks into elaborate complex chiral chemical architectures with good stereocontrol while limiting waste generation represents a priority for modern organic synthesis. ${ }^{1}$ Notably, the discovery of greener and easy to use enantioselective catalytic methods should enhance the application potential of organic transformations facilitating their transposition in the synthesis of elaborated drugs or materials. Among crucial synthetic building blocks necessary for the construction of divers chemical architectures, homoallylic alcohols 3 and $\mathbf{4}$ stand out (Scheme 1.a). They constitute privileged precursors for the synthesis of molecular patterns found in a number of natural products and drugs. For example, 3 provides a direct access to furans and pyrans while preparation of 4 constitutes a straightforward route to keto-

Scheme 1. State of the Art and Proposed Bidirectional Reductive Coupling

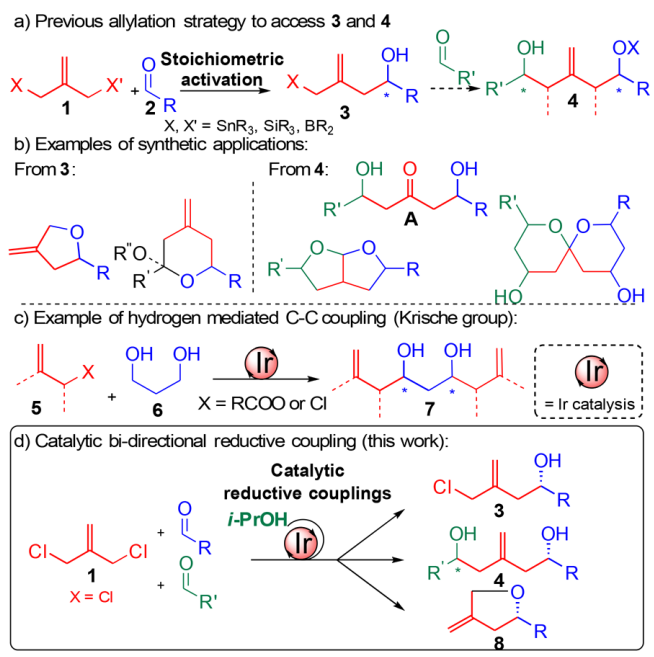

diols, 1,3,5-polyols or spiroketals (Scheme $1 \mathrm{~b}$ ). ${ }^{2}$ As a result of this pivotal synthetic interest, numerous methods have been developed for their stereoselective preparation ${ }^{3}$ mainly relying on stoichiometric metal activation and chiral additives. ${ }^{4}$ The only chiral Lewis-acid-catalyzed strategy to access alcohols 3 from 1 involved allylic stannanes obtained after initial $\mathrm{Cl}-\mathrm{Li}$ exchange. ${ }^{5}$ Access to parent ketodiols $\mathbf{A}$ can also be based on bidirectional aldolization by condensing two molecules of aldehydes with a ketone equivalent, however the direct enantioselective variant on aliphatic aldehydes still represents a challenge. ${ }^{6}$ As a result, it is clear that the development of a modular enantioselective catalytic synthesis of $\mathbf{3}$ and $\mathbf{4}$ starting from aliphatic aldehydes, occurring without the use of stoichiometric prematallated reagents and under mild conditions is highly desirable.

To circumvent waste and hazards associated with the use of stoichiometric premetalated nucleophiles, the group of Krische has proposed a wide array of coupling reactions based on the concept of alcohol mediated carbonyl addition. ${ }^{7,8}$ In a typical reaction, dehydrogenation of an alcohol by a catalytic metal complex ( $\mathrm{Ru}$ or Ir) generates a carbonyl and a metal hydride. The formed metal hydride then inserts in the allyl pronucleophile, forming a reactive metal-allyl complex able to stereoselectively add to an electrophilic carbonyl generating the desired chiral alcohol.

This type of reductive coupling is illustrated in Scheme 1c where two allyl donors 5 are condensed to a pivotal 1,3-diol 6, providing enantioenriched diols $7 .^{9}$ Interestingly, this reductive coupling chemistry can be performed by starting from an alcohol or from an aldehyde. In the latter case, addition of an environmentally friendly reductant such as 2-propanol initiates the formation of the required catalytic metal-hydride.

Continuing with our interest on bidirectional condensations, we hypothesized that 2-propanol might be used to activate commercially available 3-chloro-2-(chloromethyl)-1-propene (1) 
as pivotal pronucleophile addition to an aldehyde. This would allow for a rapid and selective generation of 3 and subsequently 4 through a bidirectional condensation with a second external aldehyde (Scheme 1d). However, the development of this bidirectional chemistry using a pivotal bis-donor might be hampered by numerous challenges. First of all, 1 should be selectively monoactivated through the use of greener hydride donors such as 2-propanol, generating 3 after addition to an aldehyde. Moreover, to apply the allylic chloride 3 in other derivatizations, it should be stable enough under the reaction conditions to avoid direct decomposition. Finally, advancing intermediate 3 to diol 4 will require an additional metal hydride insertion, resulting in a particularly sensitive hydroxyfunctionalized Ir $-\pi$-allyl complex ${ }^{10}$ prompt to evolve by a 5endo cyclization to form a methylene tetrahydrofuran 8 . This trimethylene methane (TMM) like-cycloaddition popularized by the group of Trost has, however, no efficient enantioselective version as far as aliphatic aldehydes are concerned. ${ }^{11}$ Therefore, of utmost importance for the success of our approach is that the presence of the unprotected alcohol function should neither inhibit the reactivity of the metal-allyl complex through intramolecular coordination ${ }^{12}$ nor influence the stereochemical outcome of the second nucleophilic addition allowing for a catalyst-controlled diastereodivergent process.

To initiate our study, we started investigating the reactivity of $\mathbf{1}$ with isovaleraldehyde (2a) as the electrophile for the selective synthesis of monoaddition product $3 a$ (Table 1) ${ }^{13} 2$ -

Table 1. Optimization of the Iridium-Catalyzed Addition of 1 to 2 a

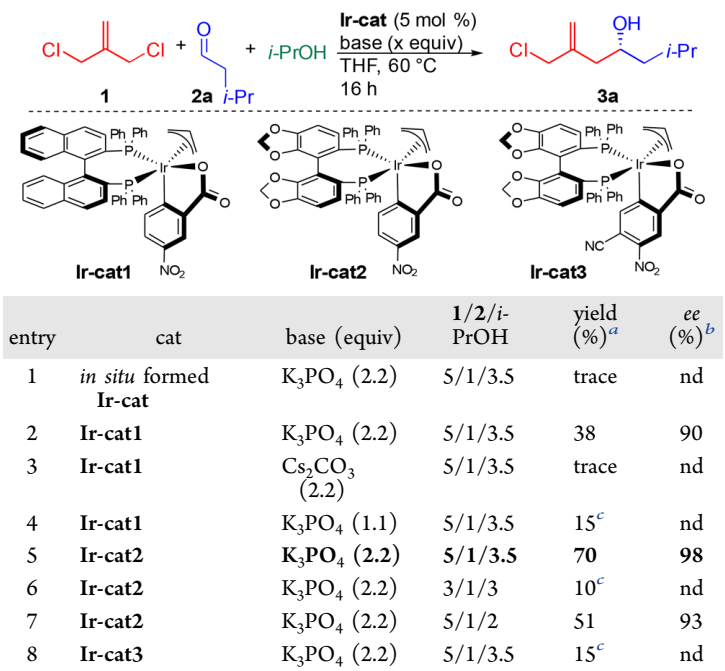

${ }^{a}$ Isolated yields. ${ }^{b}$ Enantiomeric excess determined by chiral gas chromatography. ${ }^{c} \mathrm{NMR}$ yield. $\mathrm{Nd}=$ not determined.

Propanol was chosen as the green activator in the presence of various easily accessible iridium complexes. When the active iridium complex was generated in situ from $[\operatorname{Ir}(\mathrm{COD}) \mathrm{Cl}]_{2}$, phosphine ligand, and the corresponding acid, only a trace amount of the adduct $3 \mathbf{a}$ was observed and $\mathbf{1}$ was mostly recovered (entry 1). ${ }^{14}$ However, use of $5 \mathrm{~mol} \%$ preformed Binap complex Ir-cat1 restored the reductive coupling providing $3 \mathbf{a}$ in promising $38 \%$ yield and $90 \%$ ee (entry 2).
The role of the 2.2 equiv of $\mathrm{K}_{3} \mathrm{PO}_{4}$ was crucial since use of a lower amount (1.1 equiv) or alternatively of $\mathrm{Cs}_{2} \mathrm{CO}_{3}$ considerably reduced the reactivity (entries 3 and 4 ). Turning to the use of Segphos Ir-cat2 dramatically improved the efficiency of the 2-propanol-promoted reductive coupling forming 3a in excellent $70 \%$ yield and $98 \%$ ee (entry 5). To promote the formation of $\mathbf{3 a}$ and avoid its decomposition, an excess of 1 and of 2-propanol is required in the process (entry 5 vs entries 6 and 7). It must be noticed that the use of 3.5 equiv of 2-propanol also provides higher enantiocontrol (entries 5 and 7, 98 vs. 93\% ee). Finally, use of more electron-poor aromatic ligand on the iridacycle as in Ir-cat3 reduced the reactivity forming only around $15 \%$ of $3 a$ (entry 8 ). Given previous reports on reductive couplings, the presence of traces amount of inorganic salts in Ir-cat3 reducing the reactivity cannot be excluded. ${ }^{14}$

With the optimized conditions of entry 5 in hand, we then scrutinized the scope of the monodirectional reductive coupling (Scheme 2). The 2-propanol-promoted coupling

Scheme 2. Scope of the Ir-cat2 Condensation of 1 with $2 a-h$

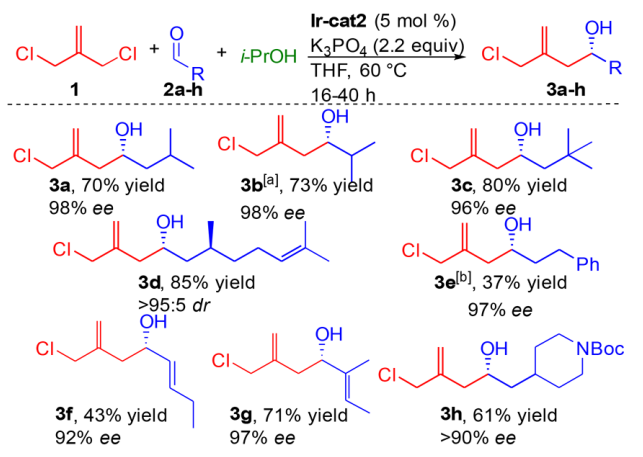

${ }^{a}$ Using $2 \mathrm{~mol} \%$ of Ir-cat2 starting from $10 \mathrm{mmol}$ of $1 .{ }^{b}$ Using additional $20 \mathrm{~mol} \% 4-\mathrm{NO}_{2}-\mathrm{BzOH}$

tolerated aldehydes with various steric substitution patterns. Aliphatic isobutyl, isopropyl, or neopentyl substituents led to the formation of the expected adducts $3 a-c$ in $70-80 \%$ yields. Moreover, the Ir-cat2 was able to induce an excellent enantiofacial discrimination during the addition providing these products in very high 96 to $98 \%$ ee. Starting from enantiopure $(S)$-citronellal, the terpenoid chain could be introduced in 3d with $85 \%$ yield and excellent diastereocontrol (>95:5 $d r$ ). Use of less sterically demanding hydrocinnamaldehyde $2 \mathrm{e}$ or trans-2-pentenal $\mathbf{2 f}$ decreased the reaction efficiency providing $\mathbf{3 e}$ and $\mathbf{3 f}$ in $37 \%$ and $43 \%$ yield, respectively but again with a high level of stereocontrol (97 and $92 \%$ ee)..$^{15}$ Finally, 2 -substituted enal $\mathbf{2 g}$ or Boc-protected amine $\mathbf{2 h}$ were well tolerated, providing $3 \mathrm{~g}$ and $3 \mathbf{h}$ in 71 and $61 \%$ yields and $>90 \%$ ee. Interestingly, demonstrating the synthetic potential of this approach, it must be pointed out that $3 \mathbf{b}$ could be prepared starting from $10 \mathrm{mmol}$ of $\mathbf{1}$ and using only $2 \mathrm{~mol} \%$ Ir-cat2.

With a practically convenient and highly enantioselective access to hydroxyl functionalized allylic chlorides 3 , we next turned our attention to the development of the challenging second functionalization. Preliminary experiments (see the Supporting Information) were conducted mixing $\mathbf{3 d}$ under the conditions of Scheme 1 and in the absence of aldehyde. Of 
importance, removing any external electrophile, evolution of 3d notably through cyclization was noticed possibly through the formation of the corresponding catalytic Ir- $\pi$-allyl complex. This is in agreement with the reactivity observed in Table 1 showing that an excess of $\mathbf{1}$ was required to improve the yield. To promote the bidirectional addition process, we thus reduced the temperature to $50{ }^{\circ} \mathrm{C}$ while placing 3 in the presence of an excess of aldehydes. Under the reductive conditions, Ir-cat2 efficiently reacted with $3 \mathbf{b}$ providing the unprotected diols $\mathbf{4 b , d , g}$ in $44-70 \%$ yield without racemization of the initial stereocenter (Scheme 3). Gratifyingly,

Scheme 3. Diastereodivergent Reductive Coupling of $3 \mathbf{b}$

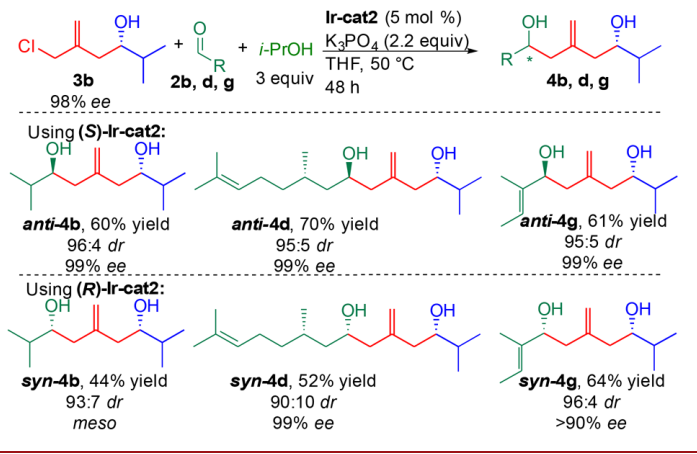

despite the presence of the unprotected alcohol in the starting material, the Ir-cat 2 was able to independently control the formation of the newly formed stereogenic center. Indeed, using the appropriate enantiomer of the catalyst, either anti or syn diols could be prepared with more than $80 \%$ diastereocontrol.

With a method able to selectively functionalize allylic chlorides 3, we focused on a last challenge, the development of a cascade direct synthesis of symmetric bis-alcohols 4 . This bidirectional reductive coupling would constitute an alternative to the ones already reported in the literature such as the condensation of two pro-nucleophiles on a central bis-alcohol (Scheme 1.b). In the present approach, an internal stoichiometric pro-nucleophile would have to react directly with two external electrophiles. As a result, for the success of this cascade, the in situ generated hydroxy functionalized allylic chloride 3, should directly react again with another aldehyde.

Gratifyingly, the selective use of Ir-cat2 allowed for the efficient condensation of structurally different aldehydes (Scheme 4). Use of 2 equiv of aldehydes with respect to each chlorine at $50{ }^{\circ} \mathrm{C}$ provided the bidirectional products $4 \mathbf{a}-$ d in $65-74 \%$ yield. Interestingly, the diols could be obtained with almost perfect enantiocontrol and $>95: 5 d r$ for $4 \mathrm{~d}$. As a result, this cascade rapidly assembles simple substrates into valuable diols key direct precursors of 1,3,5-polyols, ${ }^{16}$ easily

Scheme 4. Cascade Bidirectional Reductive Coupling of 1 desymmetrizable substrates. ${ }^{17}$ For example, anti4a could be converted through reductive ozonolysis to 1,3,5-poyol $9 \mathrm{a}$, a polyol whose synthesis was only disclosed in the racemic series (Scheme 5.a). ${ }^{6 \mathrm{~d}}$ To prove the feasibility of a direct catalytic

Scheme 5. Examples of Bidirectional Synthetic Applications and Reductive Coupling from the Alcohol Level

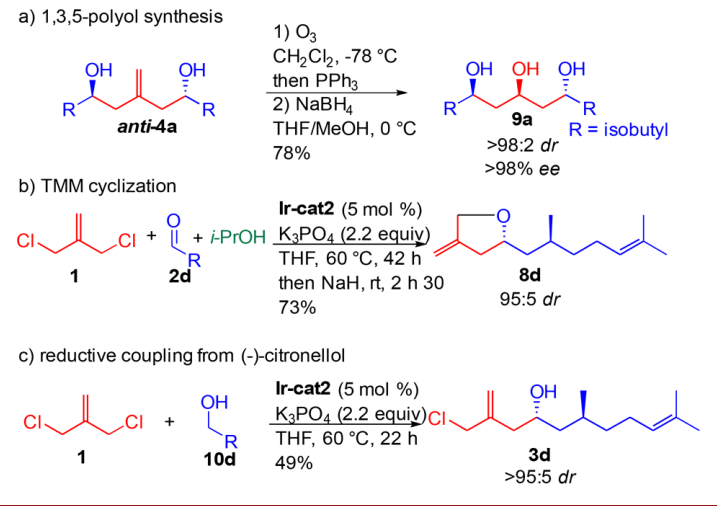

stereoselective TMM like-cycloaddition on aliphatic aldehydes, we performed the one-pot direct preparation of methylene tetrahydrofuran $\mathbf{8 d}$. Directly in situ treating the reductive coupling adduct with $\mathrm{NaH}$, the resulting TMM like-adduct could be formed in $73 \%$ overall yield (Scheme 5.b). Of importance, the reductive coupling can also be performed from the alcohol oxidation state. Preliminary experiment condensing 1 with $10 \mathrm{~d}$ provided the expected adduct $3 \mathrm{~d}$ in $49 \%$ yield and $>95: 5 d r$. Finally, determination of the absolute configuration of compounds 3 and 4 supports the enantioselection model proposed for allylation reactions using $(S)$-Ir-cat2. ${ }^{18}$

In conclusion, activation of commercially available 3-chloro2-chloromethyl-1-propene (1) by the appropriate use of a catalytic chiral iridium complex provides an innovative enantioselective reductive coupling avoiding the use of premetalated reagents. This constitutes a straightforward access to synthetically valuable bis-functionalized homoallylic alcohols with high levels of stereocontrol. The second allylic chloride functionalization involves a peculiar Ir- $\pi$-allyl complex possessing an adjacent unprotected alcohol function. Despite the poor stability of this complex, the second carbonyl addition occurs with perfect catalyst control allowing for an efficient diastereodivergent process. The discovery of an efficient way to selectively generate and react functionalized chloro-allylic alcohols opens strong perspectives for the development of other cascade reactions. It should allow a rapid and environmentally friendly construction of a broad range of valuable building blocks with important implications notably in the synthesis of natural products or drugs. Finally, we are currently investigating the strong potential of using 2-propanol reductive coupling to promote other TMM like-cycloadditions.

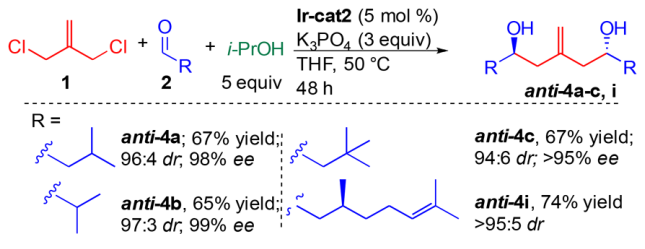




\section{- AUTHOR INFORMATION}

\section{Corresponding Author}

*E-mail: adrien.quintard@univ-amu.fr.

\section{ORCID}

Adrien Quintard: 0000-0003-0193-6524

\section{Author Contributions}

The manuscript was written through contributions of all authors. All authors have given approval to the final version of the manuscript.

Notes

The authors declare no competing financial interest.

\section{ACKNOWLEDGMENTS}

The Centre National de la Recherche Scientifique (CNRS) and the Aix-Marseille Université are gratefully acknowledged for financial support.

\section{REFERENCES}

(1) (a) Hendrickson, J. B. J. Am. Chem. Soc. 1975, 97, 5784. (b) Trost, B. M. Science 1991, 254, 1471. (c) Wender, P. A.; Miller, B. L. Nature 2009, 460, 197. (d) Gaich, T.; Baran, P. S. J. Org. Chem. 2010, 75, 4657-4673. (e) Sheldon, R. A. Chem. Soc. Rev. 2012, 41, $1437-1451$.

(2) For example of synthetic applications of 3 and 4: (a) Alonso, F.; Lorenzo, E.; Yus, M. Tetrahedron Lett. 1998, 39, 3303. (b) Barrett, A. G. M.; Braddock, D. C.; de Koning, P. D.; White, A. J. P.; Williams, D. J. J. Org. Chem. 2000, 65, 375. (c) Yu, C.-M.; Lee, J.-Y.; So, B.; Hong, J. Angew. Chem., Int. Ed. 2002, 41, 161. (d) Xie, J.; Ma, Y.; Horne, D. A. Org. Lett. 2009, 11, 5082. (e) Flowers, C. L.; Vogel, P. Chem. - Eur. J. 2010, 16, 14074. (f) Skepper, C. K.; Quach, T.; Molinski, T. F. J. Am. Chem. Soc. 2010, 132, 10286. (g) Green, A. P.; Lee, A. T. L.; Thomas, E. J. Chem. Commun. 2011, 47, 7200. (h) Williams, D. R.; Claeboe, C. D.; Liang, B.; Zorn, N.; Chow, N. S. C. Org. Lett. 2012, 14, 3866. (i) Ahlers, A; de Haro, T.; Gabor, B.; Fürstner, A. Angew. Chem., Int. Ed. 2016, 55, 1406. (j) Lorenzo, E.; Alonso, F.; Yus, M. Tetrahedron 2000, 56, 1745.

(3) For examples of racemic or diastereoselective approaches towards 3 and 4, see: (a) Degl'Innocenti, A.; Dembech, P.; Mordini, A.; Ricci, A.; Seconi, G. Synthesis 1991, 1991, 267. (b) D'Aniello, F.; Mann, A.; Mattii, D.; Taddei, M. J. Org. Chem. 1994, 59, 3762. (c) D’Aniello, F.; Mattii, D.; Taddei, M. Synlett 1993, 1993, 119. (d) Turks, M.; Fonquerne, F.; Vogel, P. Org. Lett. 2004, 6, 1053. and refs $2 \mathrm{a}$ and $2 \mathrm{~d}-\mathrm{g}$.

(4) Using stoichiometric boron prepared from transmetalation with the lithiated starting material: (a) Barrett, A. G. M.; Braddock, D. C.; de Koning, P. D. Chem. Commun. 1999, 459. and reference $2 b$. Using a stoichiometric chiral boron reagent prepared from the corresponding stannane see reference $2 \mathrm{~h}$. Using stoichiometric silylated and chiral reagents: (b) Tekle-Smith, M. A.; Williamson, K. S.; Hughes, I. F.; Leighton, J. L. Org. Lett. 2017, 19, 6024.

(5) Using stoichiometric stannanes prepared from transmetalation with the lithiated starting material see reference $2 c$, and: (a) Keck, G. E.; Yu, T.; McLaws, M. D. J. Org. Chem. 2005, 70, 2543. (b) Heumann, L. V.; Keck, G. E. A. Org. Lett. 2007, 9, 1951.

(6) See, for example: (a) Mikami, K.; Matsukawa, S.; Nagashima, M.; Funabashi, H.; Morishima, H. Tetrahedron Lett. 1997, 38, 579582. (b) Shimoda, Y.; Kubo, T.; Sugiura, M.; Kotani, S.; Nakajima, M. Angew. Chem., Int. Ed. 2013, 52, 3461. (c) Valero, G.; Ribo, J. M.; Moyano, A. Chem. - Eur. J. 2014, 20, 17395. (d) Quintard, A.; Rodriguez, J. Chem. - Eur. J. 2015, 21, 14717. (e) Kotani, S.; Kai, K.;
Shimoda, Y.; Hu, H.; Gao, S.; Sugiura, M.; Ogasawara, M.; Nakajima, M. Chem. - Asian J. 2016, 11, 376. (f) Quintard, A.; Rodriguez, J. ACS Catal. 2017, 7, 5513. (g) Kotani, S.; Kai, K.; Sugiura, M.; Nakajima, M. Org. Lett. 2017, 19, 3672. (h) Quintard, A.; Rodriguez, J. Org. Lett. 2018, 20, 5274. (i) Ricucci, A.; Rodriguez, J.; Quintard, A. Eur. J. Org. Chem. 2018, 2018, 3697. (j) Quintard, A.; Rodriguez, J. Chimia 2018, 72,580 .

(7) For reviews: (a) Ngai, M.-Y.; Kong, J.-R.; Krische, M. J. J. Org. Chem. 2007, 72, 1063. (b) Bower, J. F.; Kim, I. S.; Patman, R. L.; Krische, M. J. Angew. Chem., Int. Ed. 2009, 48, 34. (c) Ketcham, J. M.; Shin, I.; Montgomery, T. P.; Krische, M. J. Angew. Chem., Int. Ed. 2014, 53, 9142. (d) Dechert-Schmitt, A-M. R.; Schmitt, D. C.; Gao, X.; Itoh, T.; Krische, M. J. Nat. Prod. Rep. 2014, 31, 504. (e) Quintard, A.; Rodriguez, J. Chem. Commun. 2016, 52, 10456. (f) Feng, J.; Kasun, Z. A.; Krische, M. J. J. Am. Chem. Soc. 2016, 138, 5467. (g) Kim, S. W.; Zhang, W.; Krische, M. J. Acc. Chem. Res. 2017, 50, 2371.

(8) For leading references notably based on iridium complexes: (a) Kim, I. S.; Ngai, M.-Y.; Krische, M. J. J. Am. Chem. Soc. 2008, 130, 6340. (b) Kim, I. S.; Ngai, M.-Y.; Krische, M. J. J. Am. Chem. Soc. 2008, 130, 14891. (c) Kim, I. S.; Han, S. B.; Krische, M. J. J. Am. Chem. Soc. 2009, 131, 2514. (d) Dechert-Schmitt, A-M. R.; Schmitt, D. C.; Krische, M. J. Angew. Chem., Int. Ed. 2013, 52, 3195. (e) Feng, J.; Garza, V. J.; Krische, M. J. J. Am. Chem. Soc. 2014, 136, 8911.

(9) (a) Lu, Y.; Kim, I. S.; Hassan, A.; Del Valle, D. J.; Krische, M. J. Angew. Chem., Int. Ed. 2009, 48, 5018. (b) Hassan, A.; Lu, Y.; Krische, M. J. Org. Lett. 2009, 11, 3112. (c) Han, S. B.; Hassan, A.; Kim, I. S. Krische, M. J. J. Am. Chem. Soc. 2010, 132, 15559. (d) Gao, X.; Han, H.; Krische, M. J. J. Am. Chem. Soc. 2011, 133, 12795.

(10) For the reactivity of such iridium $\pi$-allyl towards nucleophilic addition: Meza, T.; Wurm, T.; Smith, L.; Kim, S. W.; Zbieg, J. R. Stivala, C. E.; Krische, M. J. J. Am. Chem. Soc. 2018, 140, 1275.

(11) For leading references: (a) Trost, B. M.; Chan, D. M. T. J. Am. Chem. Soc. 1979, 101, 6429. (b) Trost, B. M.; King, S. A. Tetrahedron Lett. 1986, 27, 5971. (c) Trost, B. M.; King, S. A.; Schmidt, T. J. Am. Chem. Soc. 1989, 111, 5902. (d) For the recent enantioselective version, see: Trost, B. M.; Bringley, D. A.; Silverman, S. M. J. Am. Chem. Soc. 2011, 133, 7664.

(12) (a) Zhang, Y. J.; Yang, J. H.; Kim, S. H.; Krische, M. J. J. Am. Chem. Soc. 2010, 132, 4562. (b) Feng, J.; Garza, V. J.; Krische, M. J. J Am. Chem. Soc. 2014, 136, 8911. (c) Wang, G.; Franke, J.; Ngo, C. Q.; Krische, M. J. J. Am. Chem. Soc. 2015, 137, 7915.

(13) When 1,1-disubstituted allyl donors are reacted, use of chloro derivatives are preferred over esters derivatives: (a) Hassan, A. Townsend, I. A.; Krische, M. J. Chem. Commun. 2011, 47, 10028 (b) Hassan, A.; Montgomery, T. P.; Krische, M. J. Chem. Commun. 2012, 48, 4692. (c) Manoni, F.; Rumo, C.; Li, L.; Harran, P. G. J. Am Chem. Soc. 2018, 140, 1280.

(14) For a discussion on the difference of reactivity between isolated and in situ formed complexes see ref $8 \mathrm{~b}$ and Gao, X.; Townsend, I. A.; Krische, M. J. J. Org. Chem. 2011, 76, 2350.

(15) Use of additional carboxylic acid was required to improve the yield, probably by avoiding undesired iridacycle decomposition.

(16) For a recent review on polyols synthesis, see: Kumar, P.; Tripathi, D.; Sharma, B. M.; Dwivedi, N. Org. Biomol. Chem. 2017, 15, 733.

(17) (a) Wang, Z.; Deschenes, D. J. J. Am. Chem. Soc. 1992, 114, 1090. (b) Zhang, Y.; Arpin, C. C.; Cullen, A. J.; Mitton-Fry, M. J.; Sammakia, T. J. Org. Chem. 2011, 76, 7641. (c) Shepherd, J. N.; Na, J.; Myles, D. C. J. Org. Chem. 1997, 62, 4558. (d) Hartmann, E. Oestreich, M. Org. Lett. 2012, 14, 2406. and refs 5a, 6f, and 6h.

(18) See the Supporting Information for the determination of the configuration and refs $7 \mathrm{a}-\mathrm{c}$ for the proposed model. 